\title{
Einkauf für Ärzte und Praxen
}

\section{(8) (28) 82}

Sparen Sie Zeit und Geld mit der Dienstleistung «Einkauf» der FMH Services:

- Bis 25\% Rabatt Sonderkonditionen der Vertragslieferanten

- Verlängerte Zahlungsfristen

- Einfache Abwicklung dank monatlicher Sammelrechnung

- Direktbestellung bei einer grossen Auswahl von Vertragslieferanten

Unsere Vertragslieferanten:

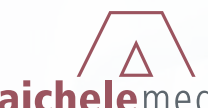

aichelemedico

$\triangle \longrightarrow$

Finn Technologies

oneprovideag

A MEMBER OF SYNLAB Y

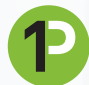

MEDICAL PARTNER

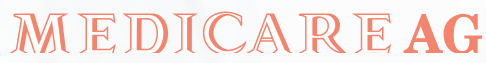

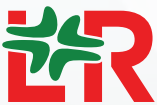

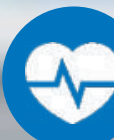

-

(18) (1) - 10

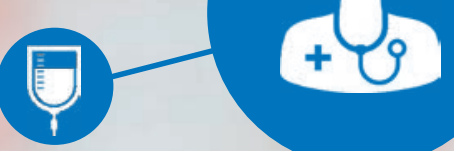

방

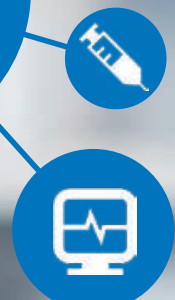

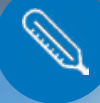
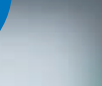